\title{
Prevalence and assessment of the risk factors of stress urinary incontinence in gynaecology out patients in a tertiary care centre
}

\author{
Ananya Bora*, Alka S Gupta \\ Department of Obstetrics and Gynaecology, Seth G S Medical College and KEM Hospital, Mumbai Maharashtra, \\ India
}

Received: 02 September 2020

Revised: 09 October 2020

Accepted: 17 October 2020

\section{*Correspondence:}

Dr. Ananya Bora,

E-mail: ananyabora3@gmail.com

Copyright: $\odot$ the author(s), publisher and licensee Medip Academy. This is an open-access article distributed under the terms of the Creative Commons Attribution Non-Commercial License, which permits unrestricted non-commercial use, distribution, and reproduction in any medium, provided the original work is properly cited.

\section{ABSTRACT}

Background: Stress urinary incontinence (SUI) is the complaint of involuntary leakage of urine during increased abdominal pressure in the absence of detrusor contraction. Although not a life-threatening condition, stress urinary incontinence causes various physical, psychological, and sexual problems for millions of women and their families. Although these conditions are highly prevalent, they are not often reported by patients. This was the reason for the study; to find out the prevalence and the associated risk factors.

Methods: A total of 400 patients presenting in the gynaecology outpatient department with various complaints were studied. A detailed history was taken, and examination was done. Urine microscopy and culture studies were done and whenever found positive; the infection was treated. Bonney's test was done on full bladder.

Results: Stress urinary incontinence was diagnosed in $41(10.30 \%)$ of the women. The most common co morbidity was found to be tuberculosis and other lung diseases. Among the study population, $4 \%$ of women had culture positive urinary tract infection.

Conclusions: Stress urinary incontinence was seen in $10.30 \%$ of the study population. It was seen more commonly among the elderly. Urine routine and microscopy was done for all patients complaining of leakage of urine or any other urinary complaints.

Keywords: Stress urinary incontinence, Urine microscopy, Culture

\section{INTRODUCTION}

The prevalence of stress urinary incontinence (SUI) in women is relatively low in early life, has a peak around the time of menopause, and then rises steadily between the ages of 60 to 80 years. As we already know, stress urinary incontinence is the complaint of involuntary leakage of urine during increased abdominal pressure in the absence of detrusor contraction. ${ }^{1}$ Prevalence of SUI is $10-45 \%$ among women. ${ }^{2,3}$ Incontinence was found to be positively increasing with parity. ${ }^{4}$ Moreover, urinary incontinence has a major impact on the health economy and is increasingly recognized as a global health concern. $^{5}$
Although, these conditions are highly prevalent they are often not reported by patients. There are several explanations for this: the leakage may not be a problem to the individual, it may be considered a part of normal ageing, expectations of successful treatments are low, patients may think they can manage on their own, or they may be too embarrassed to seek help. ${ }^{6}$ Therefore, identification of risk factors causing stress incontinence is of prime importance in suspecting the condition. Impact of factors such as aging, rise in BMI, pregnancy, route of delivery, ethnic heritage, smoking, obesity, diabetes, and other conditions that may be comorbidities or may affect the development and/or progression of stress incontinence. Not all these factors are completely 
understood in their causal relationship and magnitude, so this study aims at evaluating the risk factors along with knowing the prevalence of this condition in our tertiary care center.

\section{METHODS}

\section{Study type}

Observational, prospective, descriptive study.

\section{Study place}

King Edward Memorial hospital.

\section{Study period}

From October 2016 to October 2018.

\section{Inclusion criteria}

Inclusion criteria were, women of all age groups above the age of 18 years complaining of leaking of urine, married women, women who have been taking prior treatment in private hospital for the same, women registering for the first time in gynaecology OPD.

\section{Exclusion criteria}

Women less than 18 years of age.

A detailed history of the patient was taken by the investigator to elicit the presence, type and nature of urinary incontinence. History was taken to elicit risk factors that can precipitate or worsen her incontinence. Examination of the patient was done by one of the unit staff in the outpatient department. Routine per abdomen, per speculum and per vaginal examination of each patient giving complaint of urinary leakage were recorded. Cough impulse was checked, and Bonney's test was performed on the patients suspected to have incontinence by a qualified staff member and was documented. Urine routine microscopy was done for all and those with positive pus cells in the report were followed up with a urine culture examination. Urodynamic studies if done as and when indicated were recorded. Whenever urine microscopy and urine culture reports were found to be positive in a patient with clinically demonstrable SUI, urinary tract infection was treated, and patient was reexamined to rule out urinary tract infection (UTI) as the cause for her symptoms.

Bonney's test was performed on a full bladder. The patient was in dorsal position with her legs and abdomen covered with a drape.

The urethral opening was exposed with two gloved fingers. The patient was asked to cough. If drops of urine or spurt of urine leaked, this was recorded as cough impulse positive.
If seen, the two gloved fingers were placed in the anterior vaginal wall on either side of the urethra with care being taken not to compress the urethra. The anterior vaginal wall was lifted up to elevate the urethro-vesical junction.

The patient was asked to cough again. If there are no drops of urine expressed, Bonney's test was positive.

Positive Bonney's test signifies presence of stress urinary incontinence.

\section{Ethical approval}

The study commenced after obtaining approval from the IEC (institutional ethics committee).

1) The study population was women above 18 years of age registering in the gynaecology OPD 2) written, valid and informed consent of the patient was taken in the language the patient understands.

\section{Statistical methods}

SUI was considered as primary outcome variable. Descriptive analysis was carried out by mean and standard deviation for quantitative variables, frequency and proportion for categorical variables. Data was also represented using appropriate diagrams like bar diagram, pie diagram and box plots.

All Quantitative variables were checked for normal distribution within each category of explanatory variable by using visual inspection of histograms and normality Q-Q plots. Shapiro-wilk test was also conducted to assess normal distribution. Shapiro wilk test $\mathrm{p}$ value of $>0.05$ was considered as normal distribution.

For non-normally distributed quantitative parameters, medians and interquartile range (IQR) were compared between study groups using Mann Whitney u test (2 groups). Univariate binary logistic regression analysis was performed to test the association between the explanatory variables and outcome variables. Unadjusted Odds ratio along with $95 \% \mathrm{CI}$ is presented. Variables with statistical significance in univariate analysis were used to compute multivariate regression analysis. Adjusted odds ratio along with their $95 \% \mathrm{CI}$ is presented.

$P$ value $<0.05$ was considered statistically significant. IBM SPSS version 22 was used for statistical analysis.

\section{RESULTS}

A total of 400 subjects included in the final study. The mean age of the study population was $37.37 \pm 13.52$ years, with a minimum age of 18 years and maximum age of 88 years. The mean duration of married life was $15.43 \pm 12.83$ years, ranging from 1 to 62 years. 
The most common co morbidity reported was tuberculosis \&Other lung diseases among $16(4.0 \%)$ women. Among the study population $103(25.75 \%)$ women had attained menopause.

LSCS in the past was reported by 16 (4\%) women and 46 (11.5\%) women reported Instrumental delivery in the past. Leakage of urine was reported by 74 women in the study.

In the study population of $400,9(2.25 \%)$ had complaints of leaking of urine along with theurge to urinate at the same time. Leakage of urine was found to be associated with activities like coughing, sneezing, laughing or straining in $74(18.50 \%)$ patients. Among the study participants, 18 women had reported post void leakage of urine.

Out of 74 women with leakage of urine 3 women had complained leakage all the time, 2 women reported the need to use sanitary pads and 8 women reported interference with day to day activities (Table 1).

Table 1: Descriptive analysis of leaking urine all the time in study population $(n=74)$.

\begin{tabular}{|c|c|c|}
\hline Parameter & Frequency & Percentage \\
\hline \multicolumn{3}{|c|}{ Does it leak all the time? } \\
\hline Yes & 3 & $4.05 \%$ \\
\hline No & 71 & $95.94 \%$ \\
\hline \multicolumn{3}{|c|}{$\begin{array}{l}\text { Do you need to wear sanitary pads to prevent } \\
\text { soakage? }\end{array}$} \\
\hline Yes & 2 & $2.70 \%$ \\
\hline No & 72 & $97.29 \%$ \\
\hline \multicolumn{3}{|c|}{ Does it interfere with your day to day activities? } \\
\hline Yes & 8 & $10.81 \%$ \\
\hline No & 66 & $89.19 \%$ \\
\hline
\end{tabular}

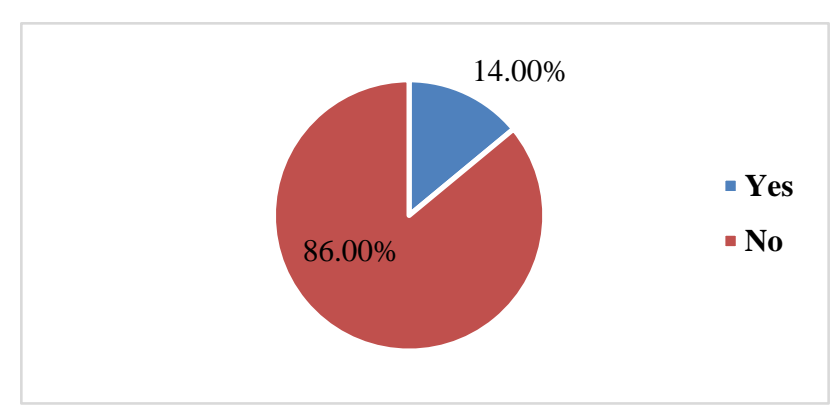

Figure 1: Cough impulse distribution in study population $(n=400)$.

Among 74 women with urinary leakage, only 5 had reported consulting a doctor for the complaint. The most common reason for not taking treatment was women not considering it as significant complaint $(30.4 \%)$, followed by personal and financial reasons (21.7 \& 13\%).
Cough impulse was positive among 56 women (Figure $1)$.

Total 45 patients had positive Bonney's test. Out of these, three had growth in culture. One Klebsiella and two E. coli and post treatment for UTI, they didn't show leakage.

Culture was done for the 112 patients out of 400; as these 112 patients had positive pus cells in their urine microscopy report.

Among the study population $16(4 \%)$ women were found to had culture positive UTI. E. coli was the most common organism isolated among $9(2.3 \%)$ women. Whenever urine culture was found to show growth of an organism, treatment was given, and patient was re-examined for SUI (Table 2).

Table 2: Descriptive analysis of Bonney's test in study population $(n=400)$.

\begin{tabular}{|lll|}
\hline Bonney's test & Frequency & Percentage \\
\hline Positive & 45 & $11.25 \%$ \\
\hline Negative & 355 & $88.75 \%$ \\
\hline
\end{tabular}

Among the 74 women complaining of urinary leak 12 $(16.2 \%)$ had culture positive UTI (Table 3 ).

Table 3: Comparison of UTI with complaints of leaking urine $(n=400)$.

\begin{tabular}{|c|c|c|c|c|}
\hline \multirow{2}{*}{$\begin{array}{l}\text { Do you leak } \\
\text { urine? }\end{array}$} & \multicolumn{2}{|l|}{ UTI } & \multirow{2}{*}{$\begin{array}{l}\text { Chi } \\
\text { square }\end{array}$} & \multirow{2}{*}{$\begin{array}{l}\text { P- } \\
\text { value }\end{array}$} \\
\hline & UTI & No UTI & & \\
\hline $\begin{array}{l}\text { Yes } \\
(\mathrm{N}=74)\end{array}$ & $\begin{array}{l}12 \\
(16.2 \%)\end{array}$ & $\begin{array}{l}62 \\
(83.8 \%)\end{array}$ & \multirow{2}{*}{35.28} & \multirow{2}{*}{$<0.001$} \\
\hline $\begin{array}{l}\text { No } \\
(\mathrm{N}=326)\end{array}$ & $4(1.2 \%)$ & $\begin{array}{l}322 \\
(98.8 \%)\end{array}$ & & \\
\hline
\end{tabular}

Among the study population, stress urinary incontinence (SUI) was diagnosed in $41(10.30 \%)$ of the women $(95 \%$ CI $7.5 \%$ to $13.7 \%$ ) (Table 4 ).

Table 4: Descriptive analysis of stress urinary incontinence in the study population $(n=400)$.

\begin{tabular}{|lll|}
$\begin{array}{l}\text { Stress Urinary } \\
\text { incontinence }\end{array}$ & Frequency & $\begin{array}{l}\text { Percentages } \\
(\mathbf{9 5 \%} \mathrm{CI})\end{array}$ \\
\hline SUI & 41 & $\begin{array}{l}10.30 \% \\
(7.5 \% \text { to } 13.7 \%)\end{array}$ \\
\hline No SUI & 359 & $\begin{array}{l}89.80 \% \\
(86.3 \%\end{array}$ \\
\hline
\end{tabular}

\section{Factors associated with sui among the study population}

The median age was higher among the women with SUI as compared to women without SUI with statistically significant difference $(<0.001)$ (Table 5). 
Table 5: Comparison of mean age between the study groups $(n=400)$.

\begin{tabular}{|c|c|c|c|}
\hline \multirow{2}{*}{ Parameter } & \multicolumn{2}{|c|}{$\begin{array}{l}\text { Stress urinary } \\
\text { incontinence }\end{array}$} & \multirow{2}{*}{$\begin{array}{l}\text { Mann- } \\
\text { Whitney } \\
\text { U test (P } \\
\text { value) }\end{array}$} \\
\hline & $\begin{array}{l}\text { Yes } \\
(\mathrm{N}=41)\end{array}$ & $\begin{array}{l}\text { No } \\
(\mathrm{N}=359)\end{array}$ & \\
\hline $\begin{array}{l}\text { Age (median } \\
\text { (IQR) }\end{array}$ & $\begin{array}{l}56(46.50, \\
71.50)\end{array}$ & $\begin{array}{l}32 \\
(26,42)\end{array}$ & $\begin{array}{l}<0.001 \\
\text { (significant) }\end{array}$ \\
\hline
\end{tabular}

The median duration since marriage was higher among the women with SUI as compared to women without SUI, with statistically significant difference $(<0.001)$.

The median weight, systolic BP were also higher among women with SUI. Even though the median diastolic BP was similar in women with and without SUI, the interquartile range was different between the two groups (Table 6).

Table 6: Comparison of marital status between the study groups $(n=400)$.

\begin{tabular}{|llll|}
\hline \multirow{2}{*}{ Parameter } & \multicolumn{2}{l|}{ Stress urinary incontinence } & Mann-Whitney U test (P value) \\
\hline Married since (In years) & Yes $(\mathbf{N}=\mathbf{4 1})$ & No $(\mathbf{N}=359)$ & $<0.001$ (significant) \\
\hline
\end{tabular}

Table 7: Comparison of SUI with menstrual history $(n=400)$.

\begin{tabular}{|c|c|c|c|}
\hline \multirow{2}{*}{ Menstrual history } & \multicolumn{2}{|c|}{ Stress urinary incontinence } & \multirow{2}{*}{ P-value } \\
\hline & Yes $(\mathrm{N}=41)$ & No $(N=359)$ & \\
\hline Pre-menopausal (N= 297) & $8(2.7 \%)$ & $289(97.3 \%)$ & \multirow{2}{*}{$<0.001$ (significant) } \\
\hline Post-menopausal $(\mathrm{N}=103)$ & $33(32.0 \%)$ & $70(68.0 \%)$ & \\
\hline
\end{tabular}

Table 8: Univariate logistic regression analysis to analyse factors associated with SUI (n=400).

\begin{tabular}{|c|c|c|c|}
\hline Factor & Un adjusted odds ratio & $95 \%$ CI of odds ratio & P value \\
\hline Age & 1.113 & $1.082-1.145$ & $<0.001$ (significant) \\
\hline Married since (In years) & 1.119 & $1.086-1.115$ & $<0.001$ (significant) \\
\hline \multicolumn{4}{|c|}{ Menstrual history (baseline $=$ Pre-menopausal) } \\
\hline Post-menopausal & 17.030 & $7.536-38.487$ & $<0.001$ (significant) \\
\hline \multicolumn{4}{|c|}{ Mode of delivery (baseline $=$ Normal vaginal) } \\
\hline Instrumental & 2.89 & $1.311-6.388$ & 0.009 (significant) \\
\hline LSCS & ND & ND & ND \\
\hline \multicolumn{4}{|c|}{ TB $/$ Lung disease $($ baseline $=$ No) } \\
\hline Yes & 8.950 & $0.549-145.861$ & 0.124 (not significant) \\
\hline \multicolumn{4}{|c|}{ Hypertension $($ baseline $=$ No $)$} \\
\hline Yes & 4.204 & $1.234-14.320$ & 0.022 (significant) \\
\hline \multicolumn{4}{|c|}{ Diabetic mellitus $($ baseline $=$ No) } \\
\hline Yes & 4.743 & $1.363-16.508$ & 0.014 (significant) \\
\hline
\end{tabular}

$\mathrm{ND}=$ Not done, Odds ratio could not be computed as there were " 0 " number of subjects with outcome in this category

Table 9: Multi variate logistic regression analysis of factors associated with SUI $(n=400)$.

\begin{tabular}{|lllll|}
\hline Parameter & Adjusted & \multicolumn{2}{l|}{ 95\% C.I. for adjusted odds ratio } \\
\hline Age & Odds ratio & Lower & Upper & P value \\
\hline Menstrual history (Baseline= Premenopausal) & 1.092 & 1.045 & 1.142 & $<0.001$ \\
\hline Instrumental delivery (baseline = No) & 1.917 & 0.529 & 6.953 & 0.322 \\
\hline Hypertension (baseline= No) & 2.04 & 0.793 & 5.267 & 0.139 \\
\hline Diabetic mellitus (baseline= No) & 0.730 & 0.177 & 3.008 & 0.663 \\
\hline Smoking lung disease (baseline= No) & 1.579 & 0.297 & 8.409 & 0.592 \\
\hline
\end{tabular}

Among women with history of LSCS, none had reported SUI. Among the 46 women with instrumentation, 10 (21.7\%) had SUI. Among the 338 women who never had instrumental delivery or LSCS in the past, 31 (9.2\%) had reported history of SUI. The difference in the proportion of SUI, between women with instrumentation and normal 
delivery was statistically significant ( $p$ value 0.012 ) (Table 8).

In multi variate logistic regression analysis the only factor, which had shown statistically significant association was age of the women, after adjusting for the effect of potential confounders (Table 9).

\section{DISCUSSION}

Urinary incontinence is a debilitating condition frequently found in the general population affecting men and women of all ages. It primarily affects women. ${ }^{7} \mathrm{UI}$ is associated with profound adverse effect on quality of life (QoL) including social, physical, sexual and mental functional impairment. ${ }^{8}$ If women at high risk of UI in later life are identified before onset of the condition, however, it might be possible to implement effective preventive measures. Hence this study was aimed at assessing the prevalence of UI and evaluating the risk factors among women attending a tertiary care center. A total of 400 women constituted the study population.

\section{Prevalence of stress urinary incontinence}

The mean age of the study population was $37.37 \pm 13.52$ years. Of the total 400 participants, 74 (18.5\%) were diagnosed with urinary incontinency. Cerruto MA et al in a systematic review reported the prevalence of UI among Europeans ranged between $16.1-68.8 \% .^{7}$ There were no large-scale studies conducted in Indian subcontinent about the prevalence of UI. A study done by Singh U et al reported the overall prevalence of UI as $21.7 \% .^{4}$ But this was slightly higher compared to our study. The possible explanation for this is that even though study by Singh U et al was a hospital-based study they have also included non-consulters in their study group. ${ }^{4}$ Whereas our study was conducted among outdoor patients attending the tertiary care center. The problem of urinary incontinence is more pronounced in India, where women usually do not seek treatment for their reproductive health problems and do not vocalize their symptoms. There is a trend of not visiting the doctor and low consultation rate among Indian women regarding such problems. ${ }^{9}$

Another study by Seshan B et al reported the prevalence of self-reported UI as $33.8 \%$ among community dwelling adult women. ${ }^{10}$ Biswas $\mathrm{B}$ et al reported the prevalence of UI as $27.7 \%$ among women aged $>50$ years in rural area. ${ }^{11}$ Walker $\mathrm{JH}$ et al in a review on incidence of urinary incontinence (UI) in developing countries reported it as $28.7 \%$ (range $5.2-70.8 \%$ ). ${ }^{12}$

In our study, out of the total 400 women's, the prevalence of stress urinary incontinence was found to be $10.3 \%$ (41/400). Among the remaining 359 patients, 9 (2.25\%) had urge urinary incontinency and $16(4 \%)$ had urinary tract infection. A higher proportion of the participants $(10.3 \%)$ with urinary tract infection were mistaken as having UI. UI exhibits as a 'tip of the iceberg phenomenon'. Subramaniam J et al reports that one in every four incontinent patients had UTI and almost half of them suffered from previous episodes of UTI. ${ }^{13}$ Thus, appropriate treatment of the existing UTI can help in the treatment of UI. Most of the participants stated that they leak urine occasionally (62\%), followed by often $(23 \%)$. In the current study Bonney's test was positive for 45 $(11.25 \%)$ in the entire study population. However, after treating UTI in the detected cases, it was found to be $10.30 \%$.

Stress UI is an involuntary loss of urine on effort or physical exertion (e.g. sporting activities), or on sneezing or coughing. SUI is a challenging condition that affects between $16 \%$ and $35 \%$ of adult women. ${ }^{14}$ The prevalence of SUI in the current study was $41(10.3 \%)$. But this was far less compared to the prevalence rate reported by Singh U et al, Prabhu SA et al, Bodhare TN et al and

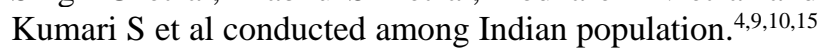
The prevalence of UI varies across regions due to variations in definitions used, study setting, age groups and populations studied. ${ }^{16}$ Contreras $\mathrm{O}$ et al reported a $50 \%$ prevalence of SUI in a review. ${ }^{17}$ In a systematic review by De Mattos Lourenco TR et al reported the prevalence of SUI ranged between $10.88 \%$ to $80 \% .^{18}$ Howard D et al suggested that functional and morphologic differences exist in the urethral sphincteric and support system of nulliparous black and white women resulting in varying SUI mechanism and thereby prevalence of SUI. ${ }^{19}$

\section{Risk factors of SUI}

\section{Age}

The mean age of the study population was $37.37 \pm 13.52$ years. When the age was compared with the incidence of SUI, the current study found significant higher odds (Unadjusted odds ratio: 1.113:95 parameters increased age was associated with significantly ( $p$ value $<0.001$ ) higher odds (1.092; 95\% CI: 1.045-1.142) of SUI. This finding was like that reported by Guin $\mathrm{G}$ et al (age 60 years or above: $83 \%$ ). Minassian VA et al reported that the prevalence of SUI peaked at the fifth decade. ${ }^{20,21}$ Hijaz A et al concluded that the advanced maternal age clearly represents an independent risk factor for postpartum SUI. ${ }^{22}$

\section{Instrumental delivery}

In the current study SUI incidence was significantly $(<0.05)$ higher among women when instruments 10 $(21.7 \%)$ ] were used for delivery compared to deliveries without use of instruments (normal vaginal delivery) 10 (2.8\%). The chance of having SUI is 2.89 (1.311-6.388) times higher in deliveries with instrumentation compared to without. Guin $\mathrm{G}$ et al reported that incidence of SUI was significantly higher ( $\mathrm{p}$ value $<0.001)$ in normal vaginal delivery $(24.83 \%)$ compared to $\operatorname{LSCS}(0 \%)$. In a cohort study by Wesnes SL et al incontinence was most 
common among women with an instrumental (36\%) or spontaneous (34\%) vaginal delivery, and lowest among women with acute $(17 \%)$ or elective $(13 \%)$ caesarean section with the prevalence of SUI being about twice that of UI. This risk increased with assisted delivery and perineal laceration. ${ }^{20,23,24}$ Roetviet $G$ et al also reported that the risk of urinary incontinence is higher among women who have had cesarean sections than among nulliparous women and is even higher among women who have had vaginal deliveries.

\section{Urinary tract infection}

In the current study urine culture was positive for 16 (4\%) of the participants. The current study found a significantly ( $\mathrm{p}$ value $<0.001)$ higher incidence of UI among UTI patients $12(16.2 \%)$ vs $4(1.2 \%)$. This was similar to that reported by Subramaniam J et al where the author reports that one in every four incontinent patients had UTI and almost half of them suffered from previous episodes of UTI. ${ }^{12}$

\section{Comorbidity}

In the current study the overall prevalence of various comorbidities was TB $(3.5 \%)$, asthma $(0.5 \%)$, HTN $(3.25 \%)$, diabetes $(3 \%)$, jaundice $(0.25)$, renal problem (0.25). $4(30.8 \%)$ participants with HTN had SUI compared to $9(69.2 \%)$ of the participant without HTN and no SUI. The $\mathrm{p}$ value was $<0.05$ and thus found to be statistically significant.

Further the study found that HTN is associated with 4.743 times higher odds (95\% CI (1.234-14.32)) of SUI ( $p$ value $<0.05$ ). Sensoy et al reported that hypertension, diabetes, family history are risk factors associated with UI. Similarly, among the participant with history of diabetes, $33.3 \%$ had SUI. ${ }^{9}$ This was found to be statistically significant. ( $p$ value $<0.05$ ). Singh $U$ et al reported that UI was significantly ( $p$ value $<0.05)$ found in diabetics $49(79.1 \%)$ vs $13(20.9)$ compared to nondiabetics. ${ }^{5}$ Stothers et al in a systematic review reported that incontinence may be a more common consequence of hyperglycemia than other microvascular complications and that other unknown processes also may underline risk factors for the development of incontinence in women with impaired glucose. ${ }^{13}$ In the current study smoking was associated with 6.36 (95\% CI: 1.717-23.56) times higher odds and asthma with 8.95 (5\% CI: 0.549-145.86) times higher odds of having SUI. In chronic respiratory diseases such as asthma, chronic obstructive pulmonary disease, cystic fibrosis and bronchiectasis, chronic cough has been implicated as a trigger of episodes of involuntary urine loss caused by successive increases in intra-abdominal pressure. We could not find any association with other comorbid factors and SUI in the current study due to low sample size.
Several other risk factors were also associated with SUI. But assessing these were beyond the scope of current study.

Overall, the current study concludes that SUI is highly prevalent among women in India. One in every ten women have complaints of leaking of urine. The most important risk factors associated with SUI in them were diabetes, hypertension, smoking, overweight, instrumentation during delivery, advanced age.

\section{Limitations}

Even though SUI is the most common type of UI found among women, only a few studies had so far assessed the prevalence of SUI and its risk factors in India. This was the major strength of the study. However, current study has many limitations. Firstly, we could not assess the association of parity with SUI, which is found to be a significant factor leading to SUI. Secondly, owing to the cross-sectional study design, we could not assess the actual association between various risk factors and SUI. The key limitation of the study is, its evaluation of the limited number of covariants, which can be associated with stress urinary incontinence among the study population. The generalizability of the study findings is limited, as the study was conducted in a single center catering to a limited geographical area.

\section{CONCLUSION}

In our study we saw that a total of 74 patients, among the 400 subjects had complained of leakage of urine. However, most of these patients had complained of leaking urine only on direct questioning. Only a few had come with leaking of urine as the chief complaint. Hence, it is concluded that it will be a better tool if leading questions for SUI were used as a part of routine history taking. It was also found that most of these patients who had the complaints of leaking of urine were actually diagnosed to have UTI. They had not come with any complaints of UTI like burning micturition, dysuria or pain in the lower abdomen. Hence, it was incidentally found. As UTI is a major risk for renal compromise, this method of questionnaire and examination and investing the patients helped to decrease that risk.

\section{Funding: No funding sources \\ Conflict of interest: None declared \\ Ethical approval: The study was approved by the Institutional Ethics Committee}

\section{REFERENCES}

1. Abrams P, Andersson KE, Birder L, Brubaker L, Cardozo L, Chapple C, et al. Members of Committees; Fourth International Consultation on Incontinence. Fourth International Consultation on Incontinence Recommendations of the International Scientific Committee: Evaluation and treatment of 
urinary incontinence, pelvic organ prolapse, and fecal incontinence. Neurourol Urodyn. 2010;29(1):213-40.

2. Hannestad YS, Rortveit G, Hunskaar S. Helpseeking and associated factors in female urinary incontinence. The Norwegian EPINCONT Study. Epidemiology of Incontinence in the County of Nord-Trondelag. Scand J Prim Health Care. 2002;20(2):102-7.

3. Grimby A, Milsom I, Molander U, Wiklund I, Ekelund $\mathrm{P}$. The influence of urinary incontinence on the quality of life of elderly women. Age Ageing. 1993;22(2):82-9.

4. Singh U, Agarwal P, Verma ML, Dalela D, Singh N, Shankhwar P. Prevalence and risk factors of urinary incontinence in Indian women: A hospital-based survey. Indian J Urol. 2013;29(1):31-6.

5. Kenton K, Mueller ER. The global burden of female pelvic floor disorders. Brit J Urol Int. 2006;98(1):15.

6. Sjostrom M, Umefjord G, Stenlund H, Carlbring P, Andersson G, Samuelsson E. Internet-based treatment of stress urinary incontinence: a randomised controlled study with focus on pelvic floor muscle training. Brit J U Int. 2013;112(3):36272.

7. Seshan V, Al Khasawneh E, Al Hashmi IH. Risk factors of urinary incontinence in women: a literature review. Int J Urolo Nurs. 2016;10(3):118-26.

8. Kumari S, Singh AJ, Jain V. Treatment seeking behavior for urinary incontinence among north Indian women. Indian J Med Sci. 2008;62(9):352-6.

9. Seshan V, Muliira JK. Self-reported urinary incontinence and factors associated with symptom severity in community dwelling adult women: implications for women's health promotion. Brit Med Centr Wom Heal. 2013;13:16.

10. Biswas B, Bhattacharyya A, Dasgupta A, Karmakar A, Mallick N, Sembiah S. Urinary incontinence, its risk factors, and quality of life: A study among women aged 50 years and above in a rural health facility of West Bengal. J Mid-life Heal. 2017;8:1306.

11. Walker GJ, Gunasekera P. Pelvic organ prolapse and incontinence in developing countries: review of prevalence and risk factors. Int Urogynecol J. 2011;22(2):127-35.

12. Subramaniam J, Eswara S, Yesudhason B. Association of Urinary Tract Infection in Married Women Presenting with Urinary Incontinence in a Hospital based Population. J Clin Diagn Res. 2016;10(3):DC10-3.
13. Stothers L, Friedman B. Risk factors for the development of stress urinary incontinence in women. Curr Urol Rep. 2011;12(5):363-9.

14. Thom DH, van den Eeden SK, Ragins AI, WasselFyr C, Vittinghof E, Subak LL, et al. Differences in prevalence of urinary incontinence by race/ethnicity. J Urol. 2006;175(1):259-64.

15. Prabhu SA, Shanbhag SS. Prevalence and risk factors of urinary incontinence in women residing in a tribal area in Maharashtra, India. J Res Health Sci. 2013;13(2):125-30.

16. de Mattos Lourenco TR, Matsuoka PK, Baracat EC, Haddad JM. Urinary incontinence in female athletes: a systematic review. Int Uro Gynecol J. 2018;29(12):1757-63.

17. Contreras Ortiz O. Stress urinary incontinence in the gynecological practice. Int J Gynaecol Obstet. 2004;86(1):S6-16.

18. Howard D, Delancey JO, Tunn R, Ashton-Miller JA. Racial differences in the structure and function of the stress urinary continence mechanism. Obstet Gynecol. 2000;95(5):713-7.

19. Sensoy N, Dogan N, Ozek B, Karaaslan L. Urinary incontinence in women: prevalence rates, risk factors and impact on quality of life. Pak J Med Sci. 2013;29(3):818-22.

20. Guin G, Choudhary A, Dadhich R. Prevalence of stress urinary incontinence and its associated risk factors amongst females attending tertiary referral centre. Int J Reprod Contracept Obstet Gynecol. 2018;7(6):2115-9.

21. Sherburn M, Guthrie JR, Dudley EC, O'Connell HE, Dennerstein L. Is incontinence associated with menopause? Obstet Gynecol. 2001;98(4):628-33.

22. Strasser H, Tiefenthaler M, Steinlechner M, Bartsch G, Konwalinka G. Urinary incontinence in the elderly and age-dependent apoptosis of rhabdosphincter cells. Lanc. 1999;354:918-9.

23. Wesnes SL, Hunskaar S, Bo K, Rortveit G. The effect of urinary incontinence status during pregnancy and delivery mode on incontinence postpartum. A cohort study. Int J Obstet Gynaecol. 2009;116(5):700-7.

24. Rortveit G, Daltveit AK, Hannestad YS, Hunskaar S, Norwegian ES. Urinary incontinence after vaginal delivery or cesarean section. $N$ Engl $J$ Med. 2003;348(10):900-7.

Cite this article as: Bora A, Gupta AS. Prevalence and assessment of the risk factors of stress urinary incontinence in gynaecology out patients in a tertiary care centre. Int J Reprod Contracept Obstet Gynecol 2020;9:4958-64. 